\title{
Measuring health equity in emergency care using routinely collected data: a systematic review
}

Kevin Morisod ( $\square$ kevin.morisod@unisante.ch )

Centre for Primary Care and Public Health (Unisanté) https://orcid.org/0000-0002-2615-5428

Xhyljeta Luta

Centre for Primary Care and Public Health (Unisanté)

Joachim Marti

Centre for Primary Care and Public Health (Unisanté)

Jacques Spycher

Centre for Primary Care and Public Health (Unisanté)

Mary Malebranche

University of Calgary Department of Medicine

Patrick Bodenmann

Centre for Primary Care and Public Health (Unisanté)

Research article

Keywords: equity, socioeconomic factors, emergency care

Posted Date: October 14th, 2020

DOl: https://doi.org/10.21203/rs.3.rs-36853/v2

License: (c) (i) This work is licensed under a Creative Commons Attribution 4.0 International License.

Read Full License

Version of Record: A version of this preprint was published at Health Equity on December $1 \mathrm{st}, 2021$. See the published version at https://doi.org/10.1089/heq.2021.0035. 


\section{Abstract}

Abstract Background: Achieving equity in health care remains a challenge for health care systems worldwide and marked inequities in access and quality of care persist. The performance assessment of health care systems is often limited to quality and efficiency indicators. Identifying indicators of health care equity is an important first step in integrating the concept of equity into assessments of health care system performance. Because emergency care serves as the interface between ambulatory and inpatient care, it is arguably an opportune setting in which to begin this process. Methods: We conducted a systematic review of administrative data-derived health care equity indicators and their association with socio-economic determinants of health (SEDH) in emergency care settings. Following PRISMA-Equity reporting guidelines, Ovid MEDLINE, EMBASE, PUBMED and Web of Science were searched for relevant studies. The outcomes of interest were indicators of health care equity and the associated SEDH they examine. Results: Among 29 studies identified, 14 equity indicators were identified and grouped into four categories that reflect the patient emergency care pathway. Total emergency department (ED) visits and ambulatory care sensitive condition-related ED visits were the two most frequently used equity indicators. The studies analysed equity based on seven SEDH: social deprivation, income, education level, social class, insurance coverage, health literacy and financial and non-financial barriers. Despite some conflicting results, all identified SEDH are associated with inequalities in access to and use of emergency care. Conclusion: The use of administrative data-derived indicators in combination with identified SEDH could improve the measurement of health care equity in emergency care settings across health care systems worldwide. Using a combination of indicators is likely to lead to a more comprehensive, wellrounded measurement of health care equity than using any one indicator in isolation. Though studies analysed focused on emergency care settings, it seems possible to extrapolate these indicators to measure equity in other areas of the health care system. Further studies elucidating root causes of health inequities in and outside the health care system are needed. .

\section{Background}

Equity is defined by the World Health Organization as "the absence of avoidable, unfair, or remediable differences among groups of people, whether those groups are defined socially, economically, demographically or geographically or by other means of stratification".(1) Applied to health care, equity means guaranteeing the "distribution of care in such a way as to get as close as feasible to an equal distribution of health".(2)

These definitions imply two essential components of equity: horizontal equity (same care for the same health need) and vertical equity (different care for different needs).(3) In order to be able to analyse equity within the health care system, most researchers assume that vertical equity is on average satisfied and focus their analysis on horizontal equity, i.e. inequalities in the use of the health care system for the same health needs.(4) 
However, achieving equity in health care remains a challenge for health care systems worldwide.(5-7) Several recent studies raise the importance of addressing the concept of equity when making decisions about health care policies and practices.(8-10) However, the performance assessment of health care systems has traditionally been limited to quality and efficiency indicators and health care decision makers remain poorly informed about equity,(8) particularly in some specific settings, such as emergency care.(10) Measuring and monitoring equity is therefore an emerging area of interest in assessing emergency care performance.(10-13)

Emergency care is a unique health care setting as it is situated at the interface of outpatient (ambulatory) care and inpatient (hospital-based) care. Identifying indicators of health care equity in this setting make it possible to assess both access to outpatient care while also highlighting differences in quality of care within hospital-based care. $(14,15)$

To ensure accessibility of quality data on relevant variables for measuring health care equity, several approaches and data could be used, from primary qualitative or quantitative data to the use of routinely collected administrative data. For this study, we have decided to focus on studies based upon routinely collected administrative data as it has two fundamental advantages in the analysis of health care equity: the achievement of near complete coverage of the target population and the possibility of disaggregation in subpopulations. Moreover, using administrative data minimizes cost and burden of response.(16)

Finally, for the purposes of this review, we have focused our analysis on studies measuring equity through socio-economic determinants of health (SEDH), i.e. the level of education, financial resources, social and material living conditions. $(17,18)$

The aim of this systematic review is to identify how health care equity is measured through the combination of administrative data-derived emergency care equity indicators and SEDH with the goal of creating a set of valuable and replicable indicators that can be used in the identification and analysis of health care equity in emergency care settings.

\section{li. Methods}

The protocol of this systematic review was published in PROPSPERO at the outset of the study. (See Additional file 1) The reporting of this systematic review was based on the PRISMA-equity guidelines.(19) (See Additional file 2)

\section{A. Inclusion/Exclusion Criteria}

We included studies reporting on health care equity indicators, and that were analysed as such, with a focus on studies that used administrative data and were conducted in emergency care settings in highincome countries. As the objective of this systematic review is to focus on health care equity in the context of emergency care and not to identify inequalities in emergency care provision between countries, a focus was placed on studies conducted in high-income countries. It is indeed difficult, in countries 
where health care resources are often lacking or insufficient, to determine whether variations in the use of care amongst certain populations are linked to inequities in access to care or whether they are the result of an overall lack of resources in the health care system. We included studies on adults (age 18 and over). If a study included both children and adults, we limited data extraction to data pertaining only to adults. We included studies regardless of whether or not a disease-specific focus was taken (for example cancer, chronic diseases or mental health). Searches were limited to articles in English, German, French, and Italian (due to the language skills of the authors) published between January 2010 and January 2019. We chose to focus on studies published after 2010 because of the significant evolution of health care equity-related literature that followed the WHO Report "Closing the gap in a generation: Health equity through action on the social determinants of health".(20)

We limited our analysis to studies looking at inequities and their associated SEDH as defined above, excluding studies looking at determinants of health such as race/ethnicity, gender or place of residence, in order to ensure consistency and comparability between studies and countries.(4)(18)

We excluded studies that did not focus on equity, as well as opinion papers, editorials, conference abstracts and study protocols.

\section{B. Search Strategy.}

The search strategy was conducted with the assistance of a medical librarian using four 4 databases: Ovid MEDLINE, EMBASE, PubMed and Web of Science. We used keywords in the field of equity, socioeconomic factors and emergency care. We combined the Medical Subject Headings (MeSH) terms "Health Services Accessibility", "Health Equity" or "Health care Disparities" with a combination of terms defining administrative data and with text words "emergency department" or "emergencies". Initial searches were conducted in November 2018 to assess the scope of the literature. The final search was conducted in January 2019. The full search strategy can be found in supplementary file 3. (See

\section{Additional file 3)}

Following the initial search, to identify any further relevant studies that were not initially captured or had not yet been published, we screened reference lists of all included studies and performed Google and Google Scholar searches using key search terms.

\section{Study Selection}

Two reviewers $(\mathrm{KM}, \mathrm{XL})$ conducted screening of articles independently and in duplicate. This was done in two stages. First by screening all titles and abstracts and second, by reviewing the full-text of all relevant articles to determine their eligibility in the final analysis. Two other reviewers (JM, PB) provided arbitration in the event of a disagreement at both stages of screening. Reasons for exclusion of articles at the fulltext screening stage were documented.

\section{Data Extraction}


Two authors $(\mathrm{KM}, \mathrm{XL})$ extracted data independently and in duplicate from included studies using Rayyan ${ }^{\circledR}$ (free online systematic review management system) and any discrepancies were resolved by consulting the two other reviewers (JM, PB). Data on the key characteristics of the studies were extracted in a predefined data extraction form, into an Exce ${ }^{\circledR}$ spreadsheet, including information about the design of the study, population, type of data, indicators of health care equity, SDEH addressed, main findings and key conclusions.

\section{E. Quality and Bias Assessment}

In the absence of international consensus on a validated tool for the analysis of the risk of bias in observational studies, we based our analysis on the ROBINS-E tool (Risk Of Bias In Non-Randomized Studies - of Exposure) derived from the validated ROBINS-I tool (Risk of Bias In Non-Randomized Studies - of Interventions).(21) Through a comprehensive analysis of the methodology applied in each study, this tool helps identify the main intra- and inter-study biases amongst included studies.

\section{F. Conceptual framework for the analysis}

To address equity, we based our analysis on a conceptual framework of access to health care, developed by Levesque and al.(22) This framework combines five dimensions of accessibility (approachability, acceptability, availability/accommodation, and affordability/appropriateness) with five corresponding abilities of the target population (ability to perceive, to seek, to reach, to pay and to engage). It provides a comprehensive approach to health care equity and the different factors that could impact it. (Figure 1)

We will use this framework to structure data extraction.

\section{lii. Results}

The initial search yielded 354 papers of which 29 were included in the final analysis. (Figure 2) Of these, $17(59 \%)$ were conducted in the United States (US), 5 (17\%) in the United Kingdom (UK), 3 (10\%) in Canada, 2 (7\%) in Australia, 1 (3\%) in Sweden and 1 (3\%) in Switzerland. Twenty-eight (97\%) were written in English and one (3\%) in French. A summary description of each study is presented in Additional file 4.

\section{Equity indicators}

The analysis of the 29 articles highlighted 14 different indicators used to assess health care equity. We categorized them into four groups according to the part of the patient care pathway they analysed, inspired by the " 5 five dimensions of accessibility" defined in the framework of Levesque et al. (22):
A. Equity indicators of poor access to outpatient care (indicators "prior to emergency care") (Group 1)
B. Equity indicators of quality of emergency care (indicators "during emergency care") (Group 2)
C. Equity indicators of clinical outcomes (indicators "following emergency care") (Group 3)
D. Global Equity indicators (Group 4) 


\section{A. Equity indicators of poor access to outpatient care (Group 1)}

This group of indicators analysed access to outpatient care through differences in emergency care consumption (poor access to outpatient care leading to excess emergency care use). Therefore, they are indirect indicators of access to outpatient care. Five indicators belonged to this group.

\section{(1) ED visits/Emergency admissions[1] rate}

With $26 \%(n=7)$ of articles using this indicator, it was the most commonly reported indicator identified in this systematic review.(23-29) It was used to highlight disparities of access to outpatient care. Since both reflect poor access to quality primary care, we have grouped them under the same indicator.

\section{(2) Ambulatory care sensitive conditions (ACSCs)[2] ED visits/ACSCs emergency admissions rate}

Also called Preventable ED visits/Preventable emergency admissions, this indicator, used in seven articles, is used as often as the previous indicator "ED visits/Emergency admissions rate". $(10,24,26,30-$ 33) It is deemed a more specific indicator than "ED visits/Emergency admissions" alone to assess disparities in access to outpatient care.

\section{(3) Frequent ED visits}

One study used this indicator considering frequent ED visits when 4 or more ED visits occurred by an individual per year.(34)

\section{(4) ED-associated initial diagnosis rate}

This indicator compared the rate of initial diagnosis of cancer in the ED between different SEDH.(35)

\section{B. Equity indicators of quality of emergency care (Group 2)}

The second group of health care equity indicators identified was indicators of quality of emergency care. They characterize disparities of care in the ED among targeted SEDH.

\section{(5) Emergency specific procedures rate}

Emergency specific procedures comprised a combination of different procedures performed during emergency care, highlighting disparities in the quality or access to care for specific emergency conditions such as a brain scan for the diagnosis of acute stroke,(36) reperfusion therapy in acute stroke,(37) and cardiac catheterization after myocardial infarction or cardiac arrest. $(38,39)$

\section{(6) Delay to diagnosis or treatment rate}

Two studies focused on disparities in time to a diagnostic procedure (CT scan for stroke)(36) and to definitive treatment (time to permanent pacemaker implementation for emergency cases).(40) 


\section{(7) Missed diagnoses in ED rate}

This indicator, used in one study, highlighted disparities of missed diagnoses of acute myocardial infarction according to insurance status or median household income.(41)

\section{Equity indicators of outcome after emergency care (Group 3)}

This third group of indicators includes indicators of outcome disparities. We identified six outcome indicators.

\section{(8) Major adverse event rate}

This indicator was used in 2 studies that analysed emergency general surgery. $(42,43)$ It represented the rate of specific complications following an emergency general surgery including cerebrovascular accident, pneumonia, pulmonary embolus, acute respiratory distress syndrome, renal failure, urinary tract infection, myocardial infarction, sepsis, septic shock and cardiac arrest.

\section{(9) In-hospital mortality and (10) failure to rescue rate}

In-hospital mortality was used to reflect the quality of care during emergency care or surgery as reported in three articles identified in our review. $(39,42,43)$ One distinguishes in-hospital mortality from failure to rescue, which occurs when a patient dies as a result of a major adverse event and seems, therefore, to be more sensitive to assess differences in quality of emergency care or surgery.(42)

\section{(11) Neurological recovery rate}

This specific indicator was used in one study analysing the neurological recovery over time of patients who presented to the ED with a cardiac arrest.(39)

\section{(12) Length of stay/Bed days (after emergency admission)}

Although these are traditional indicators of hospital care quality, they are used in one study that analysed inequities following emergency admission according to social deprivation.(44)

\section{Global Equity indicators}

As they could reflect a lack of outpatient care following a discharge post-admission and/or poor quality of care during an emergency admission, these following indicators could apply to the three different groups of indicators.

\section{(13) 30/90/365-day mortality rate}

One study analysed 30-/90-/365-day mortality following emergency admission for hip fracture, reflecting quality of ED- and hospital-based care, as well as access to and quality of ambulatory follow-up care post-discharge.(45) 
Insurance status, social deprivation, income, education level, social class, health literacy and financial and non-financial barriers. (Additional file 4) They covered the five abilities considered by Levesque et al. (Figure 1), as mentioned in brackets and italics at the end of each paragraph.

Overall, the three main SEDH used to analyse health care equity across the 29 included studies were health insurance status, indices of social deprivation and income, and eight studies (28\%) used more than one SEDH in their health care equity-focused analysis.

\section{A. Insurance status}

Insurance coverage as a relevant SEDH was approached in diverse ways amongst the 16 articles that used it including comparing outcomes between uninsured and insured individuals, $(24,30)$ between publicly and privately insured individuals, $(33,38-40,46,49)$ or between uninsured, publicly and privately insured individuals. $(23,25,35,41-43,47,48)$ Present in more than half $(55 \%)$ of the studies analysed, it is the most widely used SEDH in analyses of health care equity identified in this review. (It reflects the ability to pay in Levesque's framework).

\section{B. Social deprivation (indices of area deprivation).}

This SEDH represents the diverse social and economic conditions in which people live. This group was composed of different socio-economic deprivation indices including the "Index of Multiple Deprivation"[1], $(10,44,45)$ "Carstairs Index"[2],(31,36) "Index of Marginalization area"[3],(27) “INSPQ deprivation Index"[4], $(28,34)$ "area-based socioeconomic status quintile index"[5],(48) and "CT/10"[6] (26) These various tools take into account information about income, education, access to services, community safety, and physical environment. These indices are not assessed at the individual-level, but are instead area-based indices at the level of neighbourhoods, communities or health care regions. (Additional file $\mathbf{4}$ for details) More than half of included studies (59\%) analysed health care equity through this SEDH. (It reflects abilities to reach and to pay).

\section{Income}

To measure income differences, four studies that used this SEDH used median income household (divided into quartiles or thirds) $(41,43,46,47)$ and one used presence versus absence of a reportable income.(50) (It reflects the ability to reach and to pay).

\section{Education level}

Depending on the studies, the education level was divided into three or four categories ranging from never attended school to graduate degree.(37,49) (Additional file $\mathbf{4}$ for details) (It reflects the ability to perceive, to seek and to engage).

\section{E. Social class}


This SDEH is defined hierarchically into six classes in descending order: professional, managerial, skilled non-manual, skilled manual, semi-skilled manual, non-skilled manual. This SEDH was used in one study to analyse health care equity.(31) (It reflects the ability to reach and pay).

\section{F. Health literacy.}

In one study, health literacy was the SEDH used in the health equity-focused analysis, based on scores obtained through the Rapid Estimate of Adult Literacy in Medicine test, a reading recognition test comprised of 66 health-related words arranged in ascending order of difficulty.(32) (It reflects the ability to perceive and engage).

\section{$\underline{\text { G. Financial and non-financial barriers }}$}

In one paper, these two types of barriers were used based on subjects' responses to 14 questions (7 questions each) relating to financial concerns[7] and non-financial barriers[8].(29) (It reflects the ability to reach and to pay).

\section{Addressing health care equity through the association of emergency care indicators and SEDH}

The bias assessment revealed two significant risks of bias across studies. First of all, there is a risk for confounding related to the use of retrospectively collected administrative data used across all included studies as you can only adjust for variables that were collected. If potential confounding variables were not collected, they cannot be accounted for. For example, the almost systematic absence of precise clinical diagnoses in administrative data undermines the ability to accurately estimate the health of selected populations and therefore does not allow for a correct adjustment between compared groups.

Secondly, comparisons between studies are biased by the fact that for the same variable, data are not collected in a standardised manner. This information bias concerns all SEDH variables, but is particularly relevant for the socio-economic level, which is often analysed using indices that include many variables that differ between studies.

Because of this significant heterogeneity associated with the large number of outcomes and exposures (our systematic review highlighted 14 different indicators and 7 SEDH), we decided not to carry out a meta-analysis.

However, the last two columns of Additional file 4 present the statistical data and associated conclusions of the 29 reviewed studies. It can thus be seen that across all studies, all identified SEDH were found to be associated with statistically significant differences in emergency care indicators. Descriptive examples of associations between equity indicators and some of the main SEDH identified in this review are described below. The group of each indicator is indicated in bold and in brackets.

\section{A. Health insurance}


In a large retrospective study including over 2.2 million patients, Lines et al. demonstrated that patients with public insurance are 2.5 times more likely to have preventable ED visits (Group 1) than private patients (Rate ratio 2.53, 95\% Cl 2.49-2.56).(33) Similarly, in another large retrospective cohort of 1.3 millions patients, Metcalfe et al. highlighted a statistically significant association between in-hospital mortality (Group 3) and insurance status amongst patients presenting to hospital with acute surgical conditions requiring emergency surgery whereby uninsured patients were at significantly higher risk of death than privately insured patients (Odds Ratio 1.28, 95\% Cl 1.16-1.41).(42)

However, some studies do not show significant differences in access or quality of care based on insurance coverage. $(38,41)$ Further, among the studies comparing patients with and without insurance coverage, two have shown an increase in the use of ED (Group 1) after the introduction of public insurance coverage for previously uninsured patients. For example, DeLeire et al. found an increase in total ED visits (Group 1) of $46 \%$ ( $p$-value, $p<0.01$ ) and ACSCs ED visits (Group 1) of $38.7 \%$ ( $p$-value, $p<0.01)$ after the introduction of a public insurance (Medicaid) among low-income childless adults.(24) Authors postulate that this may be due to insurance coverage increasing one's access to outpatient care, but also to ED-based care. Similarly, Kerr et al., who compared ED visits rate (Group 1) amongst a cohort of HIV-positive patients with varying health insurance coverage $(n=4,947)$, showed that uninsured patients used the ED significantly less than privately insured patients (Incidence rate ratio (IRR) 0.65, $95 \% \mathrm{Cl}$ 0.61-0.70), but that patients with Medicaid (public insurance program in the US) used the ED more frequently (IRR 1.26, 95\% Cl 1.18-1.36).(25)

\section{B. Social deprivation}

Although social deprivation is measured by many different area-level indices among studies, it appears to be significantly associated with the three categories of indicators of emergency care identified in this review. For example, Vanasse et al. show a relative risk of ED visits (Group 1) of 3.82 among women with mood disorders in Québec of the most deprived quintile in comparison with women of the least deprived quintile (based on an index combining social and material deprivation).(28) Then Lazzarino et al., who used the Carstairs Index, highlighted a significant difference in the likelihood of having a brain scan on the day of admission (Group 2) for patients presenting to the ED with an acute stroke between the least and the most deprived quartiles (Odds ratio 0.94, 95\% Cl 0.89-0.99).(36) Similarly, Thorne et al. demonstrate a significant association between 30-day mortality (Group 4) after ED admissions for hip fracture and social deprivation quintile with patients in the most deprived quintile at higher risk than those in the least deprived quintile, based on the Index of Multiple Deprivation (Odds ratio $1.19,95 \% \mathrm{Cl}$ 1.15-1.23).(45)

\section{Income}

Findings regarding median household income were mixed across studies. Among the four studies using this SEDH, two demonstrated significant associations between median household income and emergency care indicators $(43,47)$ and the other two did not.(41,46) (See Additional file 4) 


\section{Education level and Health Literacy.}

Contrary to expectations, only two studies assess this SEDH, including one with a small sample of patients $(n=647)$, which found that lower education level was potentially associated with an increased risk of being an "emergency presenters" (defined as presenting to ED around the time of a new cancer diagnosis) (group 1).(49) The other study, by Stecksen et al. highlighted that access to reperfusion therapy (group 2) for stroke is associated with higher patient education level (Odds ratio 1.14, 95\% Cl 1.031.26).(37) Only one study analysed the impact of health literacy on potentially preventable ED visits and found that patients with poor health literacy are approximately twice as likely to have preventable ED visits (group 1) than patients with adequate health literacy, even after adjustment for relevant confounding factors (Rate Ratio 1.93, 95\% Cl 1.55-2.40).(32)

[1] A composite score originates from the following domain indices: income, employment, health, education, access to services, community safety and physical environment.

[2] An index of deprivation used in spatial epidemiology, based on four variables (Male unemployment, Lack of car ownership, Overcrowding and Low social class).

[3] A validated census- and geography-based index that measures marginalization at the level of the census dissemination area, including economic, ethno-racial, age-based and social marginalization

[4] Institut national de la santé publique du Québec (INSPQ) deprivation index: an index based on six socioeconomic indicators calculated at the dissemination area (DA) level. This index has two components, material and social. The material component is based on the proportion of people without a high school diploma, the employment-to-population ratio and the average income. The social component is based on the proportion of people living alone, the proportion of separated, divorced or widowed people and the proportion of lone-parent families

[5] Area-based SES quintile : an index of seven components based on American Community Survey (Education index, percent persons above $200 \%$ poverty line, percent persons with a blue collar job, percent persons employed, median rental, median value of owner-occupied housing unit and median household income)

[6] CT/10: a coefficient that refers to the effect of a $10 \%$ increase in the percentage of the population in the Census tract (CT) who have household incomes below $200 \%$ of the federal poverty threshold. (The poverty coefficient indicates the effect of a $10 \%$ increase in the fraction of the population living in poverty) 
[7] A set of seven self-reported financial concerns items: "insurance won't cover care", "the respondent will have to pay more than expected", "he/she will have to pay more than he/she can afford", "medications will cost too much", "not being sure about being dropped from the public healthcare program", "not knowing what the health plan covers and not knowing where to go with questions about coverage".

[8] Seven self-reported non-financial barriers including: transportation difficulties, problems making appointments, not knowing where go for care, work/family responsibilities, office/clinics not being open at suitable times, obtaining childcare and not being able to utilize one's preferred provider.

[9] For the purpose of this paper, the term "emergency admissions" is referring to a hospital admission following ED-based care or to a hospital admission for an emergency condition

[10] ACSCs are conditions for which it is believed that timely and appropriate outpatient care could prevent disease complications, or worsening of disease conditions thereby preventing ED visits and hospital admissions

\section{Iv. Discussion}

Findings of this systematic review, which identified 14 health equity indicators and 7 SEDH, suggest that administrative data allows for a broad analysis of health care equity in emergency care settings. Using these health equity indicators, each of which measure different aspects of the patient pathway through emergency care, in combination with various SEDH described, presents a promising way forward in conducting health equity analyses of health care systems. Based on these findings, we have created a conceptual framework for assessing health care equity, combining SEDH through different categories of emergency care indicators, depicted in Figure 3.

\section{Emergency care Equity indicators}

The most frequently used indicator is ED visits/Emergency admissions but due to its lack of specificity, it must be interpreted with caution as there are notably many factors that could explain differences in ED visits or emergency admissions beyond health care equity, particularly differences in general health status and prevalence of diseases.(51) ACSC ED visits/ACSC emergency admissions is arguably more specific as it focuses on ED visits/admissions that are potentially preventable with good access to primary care. $(15,52)$

The indicators comprising Group 2 (indicators of quality of emergency care) directly analyse emergency care and are therefore more specific in their measurement of health care equity in emergency care settings compared to indicators in Group 1 . We found that they are used considerably less. This may reflect difficulty in obtaining relevant data to measure these indicators through administrative datasets. However, they might be useful indicators to use in future studies analysing health care equity.

Among outcome indicators (Group 3), in-hospital mortality seems to be the most reproducible and available administrative data-derived indicator. 
Finally, 30/90/326-day mortality and ED readmission, which are more global equity indicators (Group 4) assess the lack of access to outpatient care following an ED visit, but also potential issues during the emergency care that lead to inequities in health outcome.

Due to the inherent difficulties of measuring a complex concept like health care equity and the large number of potential confounding factors, using a combination of indicators instead of one sole indicator to measure health care equity in any given health care context is more likely to result in a well-rounded assessment. As such, we suggest combining indicators across the different groups when assessing health care equity. The choice of specific indicators will depend on the context of the study, the study objectives and availability of administrative data (and relevant variables) in the health care setting of interest.

\section{Socio-Economic Determinants of Health (SEDH)}

Although median household income and education level appear to be common and reproducible measurements, many studies chose to use specific area-level indices that account for multiple domains of deprivation experienced by the target population. These indices combine different parameters to assess deprivation, such as income, employment status, living environment deprivation, and education. These indices are less reproducible than median household income since they require many more variables for their calculation (which may not be available in all health care administrative datasets), but they are arguably better at measuring inequities due to the broad domains of deprivation they assess.

To assess the accessibility of health care services, one particular SEDH emerged: insurance status. Most of the studies analysing this SEDH were published in the US. We assume that this is due to the specificities of the US health care system and the different health insurance reforms (most notably the Affordable Care Act),(53) which make this a very relevant SEDH in the US context. Despite most of the studies being US-based, this SEDH seems relevant to most health care systems in high-income countries, even those with universal health care coverage, where some individuals are able to access private insurance that covers additional benefits, therefore creating potential inequities.(54) As such, this SEDH could be used more widely than currently represented in the literature.

\section{Perspectives and implications}

An important implication of our research is the identification of four groups of indicators that can be used to analyse health eare equity in emergency care of high-income countries. As most of the indicators identified in this review are not specific to emergency care settings, it seems possible to study health care equity in other areas of the health care system of high-income countries with similar administrative dataderived indicators, as for example hospitalization,(55,56) ACSCs during the total hospital admission,(57) and wait times.(52) Such information could be useful for policy makers or health equity researchers to fill the gap in data about health care equity within different health care settings, particularly in high-income countries, using available administrative data. 
Our findings suggest that SEDH have a considerable impact on health care equity. The next step would also be to better characterize root causes for differences in emergency care utilization that lie outside the health care system. For example, in a recent study, McCormick et al. demonstrate that emergency admissions are primarily due to a higher prevalence of illness in disadvantaged areas,(51) while Pollack et al. who analysed the relationship between neighbourhood poverty and ED use in a 21-year randomized social experiment did not find a consistently significant connection between neighbourhood poverty and ED use.(58) More studies like these are needed to improve our understanding of the complex interconnectedness between SEDH, health care use and health care equity.

\section{Limitations}

Our review has some limitations that require consideration. First, the content and quality of administrative datasets are highly variable within countries (sometimes even within regions) and between countries. As such, many of the indicators identified in our review might not be available in many health care settings, reducing their generalizability and widespread applicability. However, important equity indicators such as preventable ED visits are frequently used and easily replicable between countries. Secondly, administrative data are not designed for the purpose of equity monitoring, which implies a lack of robust quality control of the collected data, a time lag in data availability, differences in concepts and definitions used between datasets limiting comparability, and the possibility of missing records. To address this, further studies of health equity indicators and SEDH using different types of datasets would be helpful for the researchers. Third, in order to define the criteria relevant to this review, it was necessary to make many normative choices before data analysis. Our focus has been indeed solely on SEDH and their associated inequities. It would also be important to analyse equity, in complementary studies, through determinants of health such as race/ethnicity, gender, or place of residence, in order to have a comprehensive picture of health care equity. As such, these results must be interpreted in the context of the concept of health care equity and the definitions we used.

Lastly, as more than the half of the studies was conducted in the US, the extrapolation of the results should be carefully interpreted.

\section{Conclusion}

Measuring health care equity should be an integral component of all comprehensive assessments of a health care system's performance. However, in order to measure health care equity, indicators for making such measurements need to be identified, as was the goal of this review. Such indicators can be used by researchers and policy makers interested in measuring health care equity through thoughtful selection of the most relevant indicators defined by the local context and stated objectives. Using a combination of indicators is likely to lead to a more comprehensive, well-rounded analysis of health care equity than using any one indicator in isolation. Though studies analysed focused on emergency care settings, it seems possible to extrapolate these indicators to measure equity in other areas of the health care system. Meta-analyses focusing on specific socio-economic determinants of health such as health insurance 
coverage, income or indices of social deprivation in combination with studies analysing factors that could influence the use of emergency care related to social inequalities would help to further characterize root causes of ongoing health care inequity in health care systems.

\section{Abbreviations}

ACSCs -Ambulatory Care Sensitive Conditions

ED - Emergency Department

SEDH - Socio-Economic Determinants of Health

US - United States

WHO - World Health Organization

\section{Declarations}

Ethics approval and consent to participate: Not applicable

Consent for publication: Not applicable

Availability of data and materials: All data generated or analysed during this study are included in the published article and its supplementary information files

Competing interests: The authors declare that they have no competing interest

Funding: Federal Office of Public Health (Bundesamt für Gesundheit). The funding body play no role in the design of the study, in the collection, analysis and interpretation of the data and in the writing of the manuscript

Authors' contributions: KM and XJ extracted, selected and analysed data under co-supervision of PB and JM. KM drafted the work. JS and XJ participated to the design of the work and the revision of the manuscript. MM, PB and JM substantively revised the manuscript. All authors read and approved the final manuscript

Acknowledgment: The authors would like to thank warmly Mr. Thomas Brauchli, librarian, for his important contribution to this review in the development of the search strategy and Dr. Patrick Taffé, biostatistician and member of Cochrane Switzerland for his valuable guidance.

\section{References}

1. World Health Organization. Equity [Internet]. www.who.int. Disponible sur: https://www.who.int/healthsystems/topics/equity/en/ 
2. Culyer AJ, Wagstaff A. Equity and equality in health and health care. $J$ Health Econ. déc 1993;12(4):431-57.

3. Braveman P. HEALTH DISPARITIES AND HEALTH EQUITY: Concepts and Measurement. 2006;30.

4. O'Donnell O, van Doorslaer E, Wagstaff A, Lindelow M. Analyzing Health Equity Using Household Survey Data: A Guide to Techniques and their Implementation [Internet]. The World Bank; 2007 [cité 29 sept 2020]. Disponible sur: http://elibrary.worldbank.org/doi/book/10.1596/978-0-8213-6933-3

5. Marmot M. The Health Gap: The Challenge of an Unequal World: the argument. Int J Epidemiol. 1 août 2017;46(4):1312-8.

6. Ostlin P, Braveman P, Dachs N, WHO Task Force on Research Priorities for Equity in Health, WHO Equity Team. Priorities for research to take forward the health equity policy agenda. Bull World Health Organ. déc 2005;83(12):948-53.

7. Marmot M, Bell R. Fair society, healthy lives. Public Health. sept 2012;126:S4-10.

8. Cookson R, Asaria M, Ali S, Ferguson B, Fleetcroft R, Goddard M, et al. Health Equity Indicators for the English NHS: a longitudinal whole-population study at the small-area level. Health Serv Deliv Res. sept 2016;4(26):1-224.

9. Mery G, Majumder S, Brown A, Dobrow MJ. What do we mean when we talk about the Triple Aim? A systematic review of evolving definitions and adaptations of the framework at the health system level. Health Policy. juin 2017;121(6):629-36.

10. Cookson R, Asaria M, Ali S, Shaw R, Doran T, Goldblatt P. Health equity monitoring for healthcare quality assurance. Soc Sci Med. févr 2018;198:148-56.

11. Lumme S, Manderbacka K, Keskimäki I. Trends of relative and absolute socioeconomic equity in access to coronary revascularisations in 1995-2010 in Finland: a register study. Int J Equity Health. déc 2017;16(1):37.

12. Bieler G, Paroz S, Faouzi M, Trueb L, Vaucher P, Althaus F, et al. Social and medical vulnerability factors of emergency department frequent users in a universal health insurance system. Acad Emerg Med Off J Soc Acad Emerg Med. janv 2012;19(1):63-8.

13. Bodenmann P, Baggio S, Iglesias K, Althaus F, Velonaki V-S, Stucki S, et al. Characterizing the vulnerability of frequent emergency department users by applying a conceptual framework: a controlled, cross-sectional study. Int J Equity Health. déc 2015;14(1):146.

14. Dowd B, Karmarker M, Swenson T, Parashuram S, Kane R, Coulam R, et al. Emergency Department Utilization as a Measure of Physician Performance. Am J Med Qual. mars 2014;29(2):135-43.

15. Rosano A, Loha CA, Falvo R, van der Zee J, Ricciardi W, Guasticchi G, et al. The relationship between avoidable hospitalization and accessibility to primary care: a systematic review. Eur J Public Health. juin 2013;23(3):356-60.

16. Statistics Canada Quality Guidelines. :89.

17. Lahelma E. Pathways between socioeconomic determinants of health. J Epidemiol Community Health. 1 avr 2004;58(4):327-32. 
18. Wilkinson RG. Socioeconomic determinants of health: Health inequalities: relative or absolute material standards? BMJ. 22 févr 1997;314(7080):591-591.

19. Burford BJ, Welch V, Waters E, Tugwell P, Moher D, O’Neill J, et al. Testing the PRISMA-Equity 2012 Reporting Guideline: the Perspectives of Systematic Review Authors. Hernandez AV, éditeur. PLoS ONE. 10 oct 2013;8(10):e75122.

20. WHO Commission on Social Determinants of Health, World Health Organization, éditeurs. Closing the gap in a generation: health equity through action on the social determinants of health: Commission on Social Determinants of Health final report. Geneva, Switzerland: World Health Organization, Commission on Social Determinants of Health; 2008. 246 p.

21. Sterne JA, Hernán MA, Reeves BC, Savović J, Berkman ND, Viswanathan $M$, et al. ROBINS-I: a tool for assessing risk of bias in non-randomised studies of interventions. BMJ. 12 oct 2016;i4919.

22. Levesque J-F, Harris MF, Russell G. Patient-centred access to health care: conceptualising access at the interface of health systems and populations. Int J Equity Health. 2013;12(1):18.

23. Davis EE, Deinard AS, Maïga EWH. Doctor, my tooth hurts: the costs of incomplete dental care in the emergency room. J Public Health Dent. 2010;70(3):205-10.

24. DeLeire T, Dague L, Leininger L, Voskuil K, Friedsam D. Wisconsin Experience Indicates That Expanding Public Insurance To Low-Income Childless Adults Has Health Care Impacts. Health Aff (Millwood). juin 2013;32(6):1037-45.

25. Kerr J, Duffus WA, Stephens T. Relationship of HIV care engagement to emergency department utilization. AIDS Care. 4 mai 2014;26(5):547-53.

26. Lines LM, Rosen AB, Ash AS. Enhancing Administrative Data to Predict Emergency Department Utilization: The Role of Neighborhood Sociodemographics. J Health Care Poor Underserved. 2017;28(4):1487-508.

27. Shulman R, Luo J, Shah BR. Mental health visits and low socio-economic status in adolescence are associated with complications of Type 1 diabetes in early adulthood: a population-based cohort study. Diabet Med J Br Diabet Assoc. 2018;35(7):920-8.

28. Vanasse A, Courteau J, Lesage A, Fleury M-J, Grégoire J-P, Moisan J, et al. [Health inequities in mood disorders based on material and social deprivation in dwelling sectors ]. Can J Psychiatry Rev Can Psychiatr. déc 2012;57(12):772-81.

29. Shippee ND, Shippee TP, Hess EP, Beebe TJ. An observational study of emergency department utilization among enrollees of Minnesota Health Care Programs: financial and non-financial barriers have different associations. BMC Health Serv Res. déc 2014;14(1):62.

30. Mazurenko O, Shen J, Shan G, Greenway J. Nevada's Medicaid expansion and admissions for ambulatory care-sensitive conditions. Am J Manag Care. 01 2018;24(5):e157-63.

31. Fairley L, Dundas R, Leyland AH. The influence of both individual and area based socioeconomic status on temporal trends in Caesarean sections in Scotland 1980-2000. 2011;10.

32. Balakrishnan MP, Herndon JB, Zhang J, Payton T, Shuster J, Carden DL. The Association of Health Literacy With Preventable Emergency Department Visits: A Cross-sectional Study. Acad Emerg Med 
Off J Soc Acad Emerg Med. 2017;24(9):1042-50.

33. Lines LM, Li N-C, Mick EO, Ash AS. Emergency Department and Primary Care Use in Massachusetts 5 Years After Health Reform. Med Care. 2019;57(2):101-8.

34. Vanasse A, Courteau J, Asghari S, Leroux D, Cloutier L. Health inequalities associated with neighbourhood deprivation in the Quebec population with hypertension in primary prevention of cardiovascular disease. Chronic Dis Inj Can. nov 2014;34(4):181-94.

35. Livingood WC, Smotherman C, Lukens-Bull K, Aldridge P, Kraemer DF, Wood DL, et al. An Elephant in the Emergency Department: Symptom of Disparities in Cancer Care. Popul Health Manag. avr 2016;19(2):95-101.

36. Lazzarino Al, Palmer W, Bottle A, Aylin P. Inequalities in Stroke Patients' Management in English Public Hospitals: A Survey on 200,000 Patients. Kleinschnitz C, éditeur. PLoS ONE. 2 mars 2011;6(3):e17219.

37. Stecksén A, Glader E-L, Asplund K, Norrving B, Eriksson M. Education Level and Inequalities in Stroke Reperfusion Therapy: Observations in the Swedish Stroke Register. Stroke. sept 2014;45(9):2762-8.

38. Berlin C, Jüni P, Endrich O, Zwahlen M. Revascularization Treatment of Emergency Patients with Acute ST-Segment Elevation Myocardial Infarction in Switzerland: Results from a Nationwide, CrossSectional Study in Switzerland for 2010-2011. Ahrens I, éditeur. PLOS ONE. 14 avr 2016;11(4):e0153326.

39. Casey SD, Mumma BE. Sex, race, and insurance status differences in hospital treatment and outcomes following out-of-hospital cardiac arrest. Resuscitation. 2018;126:125-9.

40. Bradshaw PJ, Stobie P, Einarsdóttir K, Briffa TG, Hobbs MST. Using quality indicators to compare outcomes of permanent cardiac pacemaker implantation among publicly and privately funded patients. Intern Med J. août 2015;45(8):813-20.

41. Moy E, Barrett M, Coffey R, Hines AL, Newman-Toker DE. Missed diagnoses of acute myocardial infarction in the emergency department: variation by patient and facility characteristics. Diagn Berl Ger. 1 févr 2015;2(1):29-40.

42. Metcalfe D, Castillo-Angeles M, Olufajo OA, Rios-Diaz AJ, Salim A, Haider AH, et al. Failure to rescue and disparities in emergency general surgery. J Surg Res. nov 2018;231:62-8.

43. Shah AA, Haider AH, Zogg CK, Schwartz DA, Haut ER, Zafar SN, et al. National estimates of predictors of outcomes for emergency general surgery. J Trauma Acute Care Surg. mars 2015;78(3):482-90; discussion 490-491.

44. Levin KA, Crighton EM. The Reshaping Care for Older People programme and changes in unscheduled hospital care: Analysis of routinely collected hospital data. Maturitas. sept 2017; 103:23-31.

45. Thorne K, Johansen A, Akbari A, Williams JG, Roberts SE. The impact of social deprivation on mortality following hip fracture in England and Wales: a record linkage study. Osteoporos Int J Establ Result Coop Eur Found Osteoporos Natl Osteoporos Found USA. 2016;27(9):2727-37. 
46. Finnegan MA, Shaffer R, Remington A, Kwong J, Curtin C, Hernandez-Boussard T. Emergency Department Visits Following Elective Total Hip and Knee Replacement Surgery: Identifying Gaps in Continuity of Care. J Bone Joint Surg Am. 21 juin 2017;99(12):1005-12.

47. Ladha KS, Young JH, Ng DK, Efron DT, Haider AH. Factors affecting the likelihood of presentation to the emergency department of trauma patients after discharge. Ann Emerg Med. nov 2011;58(5):431-7.

48. Whitney RL, Bell JF, Tancredi DJ, Romano PS, Bold RJ, Joseph JG. Hospitalization Rates and Predictors of Rehospitalization Among Individuals With Advanced Cancer in the Year After Diagnosis. J Clin Oncol Off J Am Soc Clin Oncol. 1 nov 2017;35(31):3610-7.

49. Yap S, Goldsbury D, Yap ML, Yuill S, Rankin N, Weber M, et al. Patterns of care and emergency presentations for people with non-small cell lung cancer in New South Wales, Australia: A populationbased study. Lung Cancer Amst Neth. 2018;122:171-9.

50. Singhal A, Momany ET, Jones MP, Caplan DJ, Kuthy RA, Buresh CT, et al. Dental care after an emergency department visit for dental problems among adults enrolled in Medicaid. J Am Dent Assoc. févr 2016;147(2):111-9.

51. McCormick B, Hill P-S, Redding S. Comparative morbidities and the share of emergencies in hospital admissions in deprived areas: a method and evidence from English administrative data. BMJ Open. août 2018;8(8):e022573.

52. Langford KM, Bottle A, Aylin PP, Ward $\mathrm{H}$. Using routine data to monitor inequalities in an acute trust: a retrospective study. BMC Health Serv Res. déc 2012;12(1):104.

53. Mclntyre A, Song Z. The US Affordable Care Act: Reflections and directions at the close of a decade. PLOS Med. 26 févr 2019;16(2):e1002752.

54. Nay O, Béjean S, Benamouzig D, Bergeron H, Castel P, Ventelou B. Achieving universal health coverage in France: policy reforms and the challenge of inequalities. Lancet Lond Engl. 28 mai 2016;387(10034):2236-49.

55. Newman KL, Lynch RJ, Adams AB, Zhang R, Pastan SO, Patzer RE. Hospitalization Among Individuals Waitlisted For Kidney Transplant. Transplantation. 2017;101(12):2913-23.

56. Lama G, Alcala E, Capitman JA. Poor People Are Hospitalized Three Times More for Mental Health Services than the Non-Poor in Central Valley California. Healthc Basel Switz. 12 janv 2018;6(1).

57. McCormick D, Hanchate AD, Lasser KE, Manze MG, Lin M, Chu C, et al. Effect of Massachusetts healthcare reform on racial and ethnic disparities in admissions to hospital for ambulatory care sensitive conditions: retrospective analysis of hospital episode statistics. BMJ. 1 avr 2015;350(mar30 9):h1480-h1480.

58. Pollack CE, Du S, Blackford AL, Herring B. Experiment To Decrease Neighborhood Poverty Had Limited Effects On Emergency Department Use. Health Aff (Millwood). 1 sept 2019;38(9):1442-50.

\section{Figures}




\section{Health Care System}

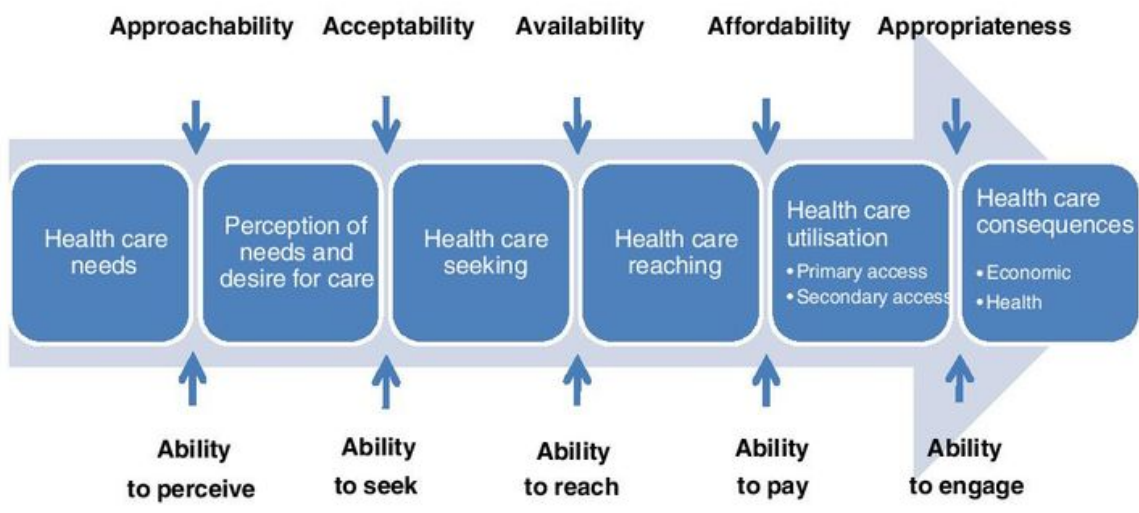

Patients

\section{Figure 1}

Framework of health care equity, adapted by Levesque et al. 


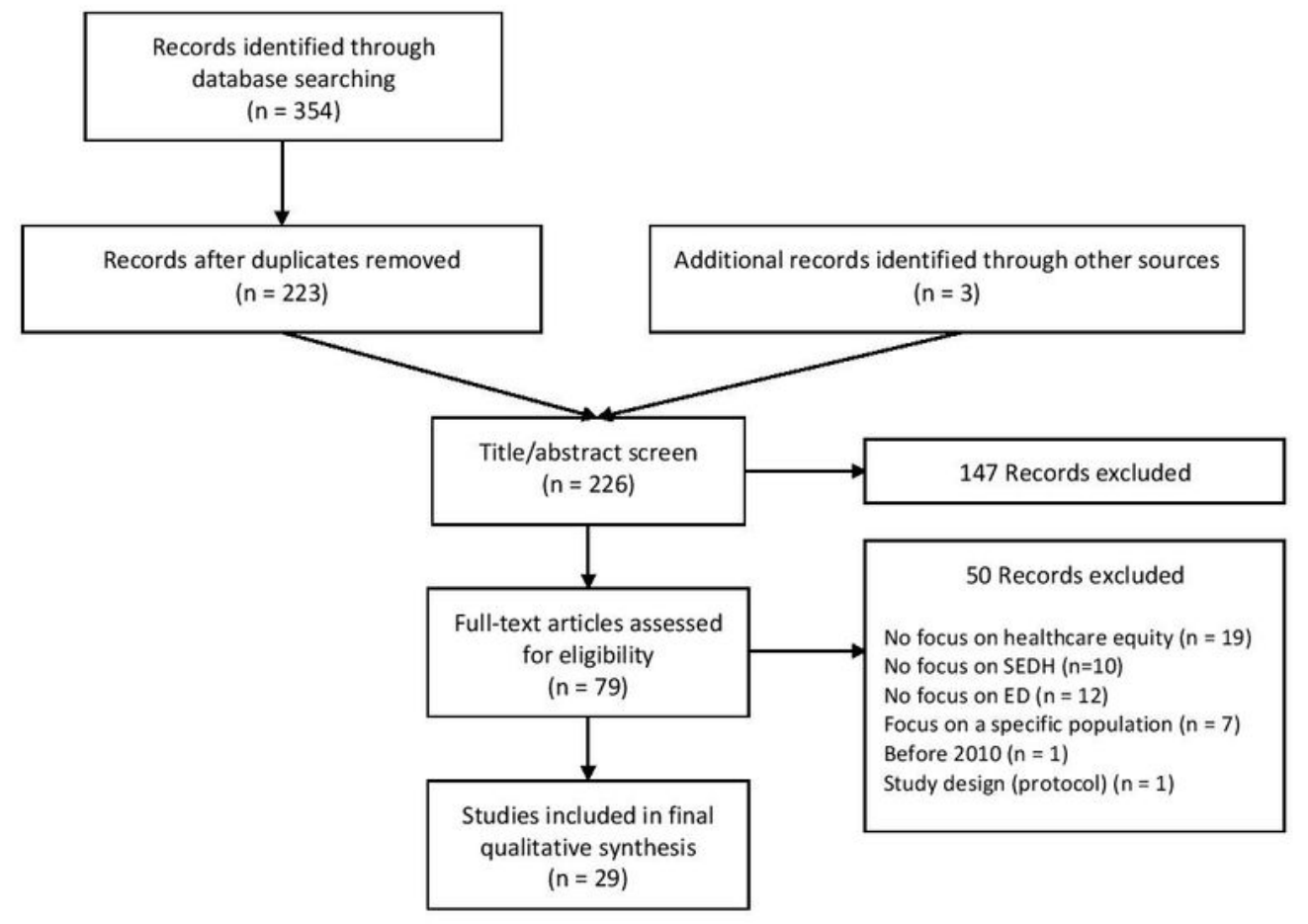

Figure 2

Flow diagram of literature research 


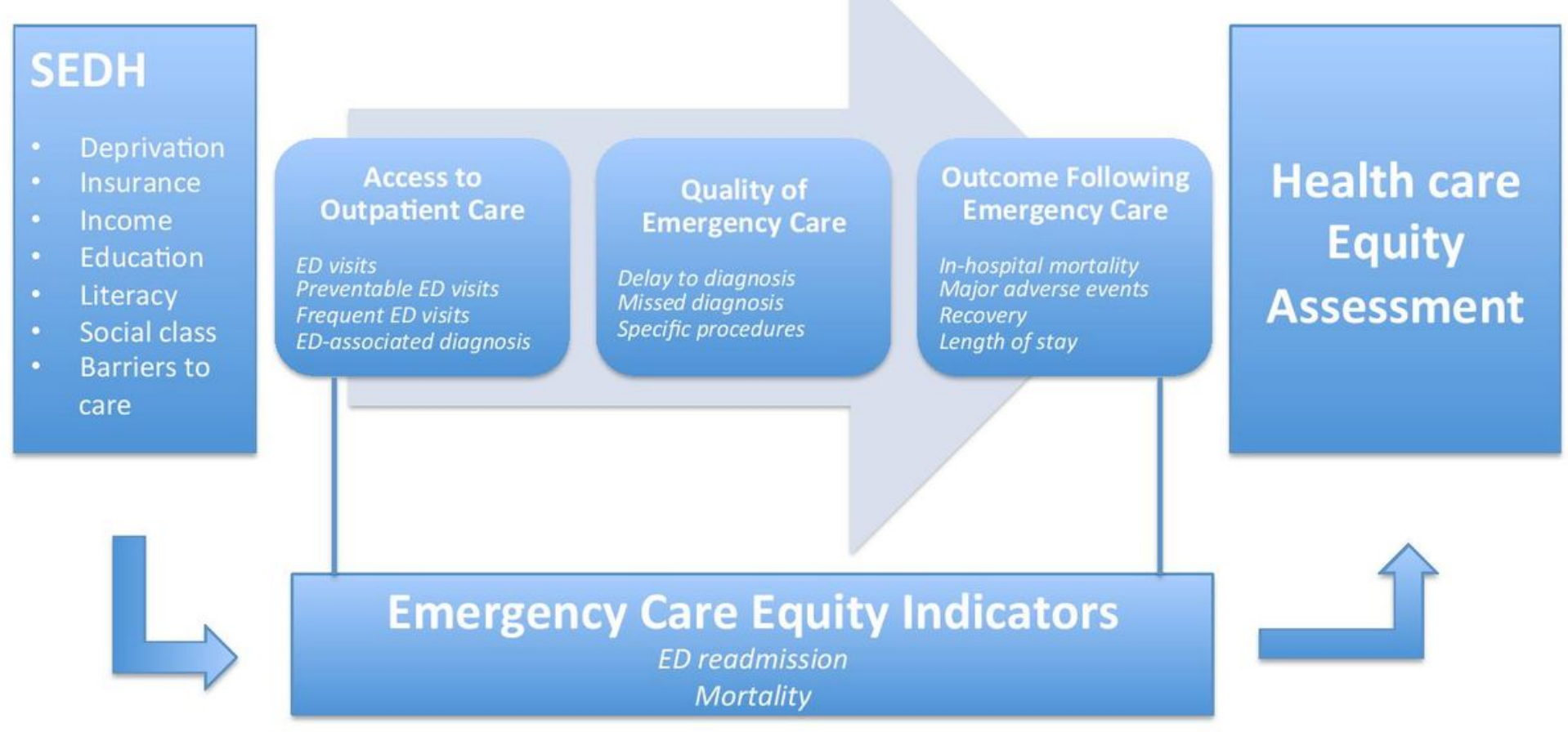

Figure 3

Conceptual model of Assessment of Health care Equity 